\title{
Transforming health through sustainable development
}

\author{
Sagar Dugani MD PhD, Trevor Duke MD, Niranjan Kissoon MBBS
}

$\mathrm{A}$ $\mathrm{t}$ the United Nations Sustainable Development Summit, held Sept. 25-27, 2015, world leaders formally adopted 17 "sustainable development goals" (SDGs) to guide global development efforts over the next 15 years $(2015-2030){ }^{1}$ The goals build on the "millennium development goals" adopted in 2000 by 189 member states to reduce global inequities in health, education and human development. Compared with the millennium development goals, which comprised 8 goals and 21 targets, the SDGs are supremely ambitious and unprecedented in scope, with 17 goals and 169 targets, intended to shift the world to a resilient path of human development that is sustainable and protects the environment. ${ }^{1,2}$ The SDGs are integrated, indivisible and universally applicable and focus efforts in five areas: people, planet, prosperity, peace and partnership. ${ }^{1}$ In this commentary, we focus on the health targets; however, success in achieving them will depend on gains made in the other 16 goals, including ending poverty and hunger; promoting educational, economic and gender equality; and building resilient structures that protect ecosystems, water bodies and the climate. ${ }^{1}$

Do the SDGs promise too much, and can the world deliver on them? Goal 3 explicitly focuses on health and aims to "ensure healthy lives and promote well-being for all at all ages." It comprises 13 targets, which include quantitative targets to reduce maternal, neonatal and child [under-five] mortality, as well as premature deaths from noncommunicable diseases and road traffic crashes. ${ }^{1}$ Goal 3 also includes general targets on reducing narcotic and alcohol abuse, ensuring access to reproductive health, ending infectious disease epidemics, strengthening the Framework Convention on Tobacco Control, ${ }^{3}$ building capacity of the health workforce, and ensuring access to essential medications and vaccinations.

That we must attain these targets may seem intuitive, but the mechanism by which they should be achieved remains less clear. Given the global variation in geopolitics, economics and culture, the SDGs offer little direction on how a low- or middle-income country could build a strong primary health care system to deliver basic health services, ensure financial health protection to its people, make available essential medications, treat substance and narcotic drug abuse, or identify the stakeholders to achieve the goals. Without further guidance, many countries will find it challenging to achieve these targets. Specific time-bound indicators are best decided locally or nationally. Moreover, progress is rarely linear, and as conditions and outcomes improve, it becomes more difficult to achieve similar proportional gains.

Predicting SDG outcomes is a risky endeavour, but an examination of millennium development goals 4 and 5 may offer some clues. Fifteen years ago, the millennium development goals exposed global inequities in maternal and child health and strived for a two-thirds reduction in child mortality (goal 4) and a three-quarter reduction in maternal mortality (goal 5) by $2015 .{ }^{4} \mathrm{In}$ evaluating child mortality in 75 countries accounting for more than $90 \%$ of childhood mortality, it is estimated that 17 and 9 countries achieved goals 4 and 5, respectively. ${ }^{5}$ Globally, child mortality has fallen from 91 deaths per 1000 live births in 1990 to 43 deaths per 1000 in $2015,{ }^{6}$ and China has lifted 470 million people out of extreme poverty. ${ }^{7}$ Thus, despite impressive overall gains, progress has been patchy, and countries with high mortality have not achieved their targets.

The SDGs reflect the aspirational nature of the millennium development goals. Therefore, it is unreasonable to believe that the SDGs will catalyze a seismic shift in policies of governments. Although all countries need to accelerate efforts toward achieving the goals, urgent action is required in sub-Saharan Africa and South Asia, where mortality remains high. ${ }^{6}$ It is antici-

\section{- KEY POINTS}

- The sustainable development goals (SDGs) build on the millennium development goals and will guide global development from 2015 to 2030.

- The SDGs comprise 17 goals and 169 targets to address five areas: people, planet, prosperity, peace and partnership.

- Goal 3 has 13 targets that explicitly identify quantitative and qualitative health targets.

- Countries will need to design specific areas of focus, agendas and mechanisms to achieve the 17 goals. 
pated that the SDGs will sustain focus on reducing global maternal and child mortality.

Although the SDGs are ambitious and broad in scope, they also appropriately reflect the complex integration and interdependence of different aspects of human development, education, health and the environment. For instance, implementation of community-based strategies on empowerment, education and nutrition helped to prevent $58 \%$ of maternal, newborn and child deaths in Pakistan, ${ }^{8}$ and sustainment of this reduction in mortality could help achieve the SDGs. ${ }^{9}$ Globally, traffic-related injuries remain a major cause of death ${ }^{2}$ that could be prevented with investment in road infrastructure and development of traffic regulatory policies.

Further, achieving the SDGs will require a strong workforce of community health workers, child health nurses, physicians, midwives and pharmacists, among others. The World Health Organization estimates that the global workforce shortage will increase by $80 \%$, to 12.9 million, over the next two decades, ${ }^{10}$ and countries will have to invest human and financial resources to response adequately to the needs of their people.

Although global targets are useful, countryspecific targets could be more helpful in ensuring that the SDGs are achieved ${ }^{11}$ as ministries and policy-makers design their health agendas. A whole-of-government approach is needed.

This approach itself is ambitious, but it will be insufficient if civil society is not strongly engaged. To this end, the United Nations Development Programme is increasing global engagement through various media, including the Internet, radio, television and cinemas.

Countries will have to identify their unique challenges, conceptualize a framework for improvement, develop an agenda for development and incorporate strategies to monitor their progress and challenges. The SDG framework provides quantitative targets for many of the goals; however, where quantitative targets are not provided, countries will be required to develop targets and monitor their progress toward achieving them. As they move toward achieving the SDG goals, countries should remain transparent about the lessons learned and challenges faced in working on the millennium development goals, so others can avoid pitfalls and catalyze progress toward achieving the SDGs.

The SDGs identify that common challenges are faced by the global community. They also serve as an important reminder of the international role that high-income countries such as Canada and Australia could play in helping other countries develop health systems, knowledge platforms and frameworks toward achieving the goals. As we share the finite resources of our planet, the SDGs remind us that sustained human development will result from understanding our interdependence, strengthening our shared physical environment, empowering individuals to attain optimal health and remain economically productive, and protecting our natural resources for the present and future generations.

\section{References}

1. Transforming our world: the 2030 agenda for sustainable development [preamble]. New York: Sustainable Development Knowledge Platform, Division for Sustainable Development, Department of Economic and Social Affairs - United Nations; 2015. Available: https://sustainabledevelopment.un.org/post2015 /transformingourworld (accessed 2015 Oct. 1).

2. Murray CJL. Shifting to sustainable development goals implications for global health. N Engl J Med 2015;373:1390-3.

3. Jha P, Peto R. Global effects of smoking, of quitting, and of taxing tobacco. N Engl J Med 2014;370:60-8.

4. Kissoon N, Dugani S, Bhutta ZA. Maternal and child health: gains, but a long journey ahead. CMAJ 2015;187:E471-2.

5. Independent Expert Review Group (iERG). Every woman, every child: strengthening equity and dignity through health - second report of the iERG on information and accountability for women's and children's health. Geneva: World Health Organization; 2013. Available: www.who.int/woman_child_accountability/ierg/ reports/2013/iERG2013-ExecutiveSummary-EN.pdf (accessed 2016 Feb. 22).

6. You D, Hug L, Ejdemyr S, et al. Global, regional, and national levels and trends in under-5 mortality between 1990 and 2015 , with scenario-based projections to 2030: a systematic analysis by the UN Inter-agency Group for Child Mortality Estimation. Lancet 2015;386:2275-86.

7. China's success on millennium development goals provides an example for others to follow for the post-2015 development agenda, says new UNDP report. New York: United Nations Development Programme; 2015. Available: www.undp.org/content/ undp/en/home/presscenter/articles/2015/02/17/china-s-success-on -millennium-development-goals-provides-an-example-for-others -to-follow-for-the-post-2015-development-agenda-says-new-undp -report0.html (accessed 2015 Oct. 1).

8. Bhutta ZA, Hafeez A, Rizvi A, et al. Reproductive, maternal, newborn, and child health in Pakistan: challenges and opportunities. Lancet 2013;381:2207-18.

9. Brown NJ, Platt MPW, Beattie RM. Women, children, and global public health: beyond the millennium development goals. BMJ 2015;350:h1755.

10. A universal truth: no health without a workforce. Geneva: Global Health Workforce Alliance and World Health Organization; 2013. Available: www.who.int/workforcealliance/knowledge/resources/ hrhreport2013/en/ (accessed 2015 Oct. 1)

11. Cohen RL, Bishai DM, Alfonso YN, et al. Post-2015 health goals: Could country-specific targets supplement global ones? Lancet Glob Health 2014;2:e373-4.

Affiliations: Division of Internal Medicine (Dugani), St. Michael's Hospital and University of Toronto, Toronto, Ont.; Centre for International Child Health (Duke), Department of Paediatrics, University of Melbourne; Murdoch Childrens Research Institute (Duke), Royal Children's Hospital, Melbourne, Australia; University of British Columbia and British Columbia Children's Hospital (Kissoon), Vancouver, BC

Contributors: All of the authors contributed to the drafting and revising of the manuscript for important intellectual content, approved the final version to be published and agreed to act as guarantors of the work. 